\title{
Study on the Correlation between Stock Market and Macro Economy in China
}

\author{
Shengjun Li, Xiumin Zhao \\ XingTai University,Xing'tai,54001 \\ hunter2011@foxmail.com
}

Keywords: Stock market, Macroeconomics; Empirical test.

\begin{abstract}
In order to characterize the correlation between stock market and the macro-economy in China, the study used 20 years data from 1995 to 2014 to analyze, by means of Johansen cointegration method and Granger causality test to verify whether there is departure between China's stock market and economic growth. Test results show that: in general, China's stock market is positively correlated with the level of economic growth, but the stock market's function is still its most basic financing function in a market economy. Only by continuing to strengthen supervision on listed companies, improving the quality of listed companies, increasing market supervision and cracking down on illegal market discipline violations, can it make the stock market play its resource allocation function. With the continuous growth and system gradual improvement of China's stock market, it will play a more and more far-reaching effect in China's economic growth.
\end{abstract}

\section{Introduction}

The relationship between macroeconomic and stock market volatility has been closely watched by financial research scholars at home and abroad. Economists generally believe that there is a close relationship between macroeconomic and stock market, but most studies focus only on shallow fluctuating relationship between macroeconomic variables and stock market index. it still need to be further deepened for the understanding of its inherent structural reasons. China's economy has become an important driving force to promote world economic development, and as an emerging market, China's stock market has an important role in warning and forecast for macroeconomic fluctuations, in order to maintain steady and rapid economic development, it is necessary to conduct in-depth studies on the macroeconomic and stock market volatility, especially in recent years, macro economy and stock market volatility presents quite complex relationship, and stock market volatility is more uncertainty. Therefore, clearing static correlation structure between them, analyze the dynamic relationship has become particularly important and it also has theoretical and practical significance.

\section{Unit root test}

Additional items test. DF test is proposed in 1979 by the Dick and Fowler, and the test method is as follows:

$\mathrm{HO}: \quad \beta=1 \quad\left(\mathrm{y}_{\mathrm{t}}\right.$ is not smooth $) \quad \mathrm{Ht}: \quad \beta<1 \quad$ ( $\mathrm{y}_{\mathrm{t}}$ is smooth)

Under the condition the assumption is established, DF test statistic is:

$$
D F=\frac{\widehat{\beta}-1}{\mathrm{~s}(\widehat{\beta})}=\frac{\widehat{\beta}-1}{\mathrm{~s}(\widehat{\mathrm{u}}) / \sqrt{\sum_{\mathrm{t}=2}^{T}\left(y_{t}-1\right)^{2}}}
$$

In this equation:

$$
\mathrm{s}(\hat{\mathrm{u}})=\sqrt{\frac{1}{T-1} \sum_{\mathrm{t}=2}^{T} \widehat{\mathrm{u}}_{\mathrm{t}}^{2}}
$$

If the DF is not less than the critical value, it accepts $y_{t}$ is not stable, otherwise, to accept $y_{t}$ is stable. 
Stability test results. This article conducts unit root test or adding DF test for each variable, Wherein the determining of the hysteresis item using AIC guidelines. During the inspection, inspection forms takes Trend and Intercept. Test according to the above unit root test method, and the results obtained are shown in Table 1.

Table 1 stationary test results of each time series

\begin{tabular}{|c|c|c|c|c|c|}
\hline & & $\mathrm{Ln}(\mathrm{ca})$ & $\mathrm{Ln}(\mathrm{tu})$ & $\mathrm{Ln}(\mathrm{va})$ & $\mathrm{Ln}(\mathrm{gdpg})$ \\
\hline \multirow{3}{*}{$\begin{array}{c}\text { Test formula } \\
\text { contains }\end{array}$} & ADF value & -463 & -2.81 & -2.21 & -1.94 \\
\cline { 2 - 6 } $\begin{array}{c}\text { intercept and } \\
\text { trend items }\end{array}$ & $1 \%$ threshold & -4.66 & -4.53 & -4.99 & -4.53 \\
\cline { 2 - 6 } & $5 \%$ threshold & -3.67 & -3.67 & -3.87 & -3.67 \\
\cline { 2 - 6 } & $10 \%$ threshold & -3.27 & -3.27 & -3.38 & -3.28 \\
\cline { 2 - 6 } & lag order & 2 & 2 & 7 & 2 \\
\cline { 2 - 6 } & conclusion & & non-stationary & non-stationary & non-stationary \\
\hline
\end{tabular}

As it can be seen from Table 1, each of the selected indicators failed to pass the significance level of 5\% significance test, which stats that they are not stationary time series. Ln (ca) got though the $1 \%$ significance test, so it is stable, but the other variables are non-stationary, it must be a first-order differential to adjust the time sequence. Perform the same unit root test of time after the first difference sequence. From the test results can be seen: after the first difference, each time series have passed the significance level of $1 \%$ China stock market and economic growth empirical analysis of significant test, which indicates that table data satisfies Granger causality test and co-integration test requirements, so it can be used for testing.

\section{Cointegration test}

Johnson test. In vector autoregression model of multiple variables, many relevant variables are intertwined, forming a plurality of co-integration relationship, and it is often difficult to separate from a clear cointegration, for the cointegrating relationship, this paper used Johnson multiple cointegration methods. Test method proposed by Johnson about coefficient matrix H Cointegrated likelihood ratio (LR), and cointegration likelihood ratio test the hypothesis is as follows:

$\mathrm{HO}:$ at most $\mathrm{r}$ cointegrating relations

$\mathrm{Ht}: \mathrm{m}$ cointegrating relations

Test track statistics: $Q r=-T \sum_{\mathrm{i}=\gamma+1}^{\mathrm{m}} \log \left(1-\lambda_{\mathrm{i}}\right)$

Wherein, $\lambda_{\mathrm{i}}$ is the magnitude of the eigenvalues, $\mathrm{T}$ is the total number of observations. It should be noted that this is not a stand-alone test, but a series of tests corresponding to different values, starting from the inspection absence of any cointegration, then at most one cointegrating relationship, until most $\mathrm{m}-1$ cointegrating relations, conducted a total of $\mathrm{m}$ times test the alternative hypothesis unchanged.

Cointegration test results. First, judging from the test of 0.01 level, because the trace test statistics show $86.88>54.68,9.59>19.94,31.83<35.46,2.40<3.84$ and the maximum eigenvalue test statistics show 55.06 $>32.99,7.55<18.90,2.40<6.78,21.88<25.78$, therefore, $\operatorname{Ln}$ (gdpg) and $\operatorname{Ln}(\mathrm{va})$, $\mathrm{Ln}$ (gdpg) and $\mathrm{Ln}(\mathrm{ca})$ series have cointegration relationship.

Meanwhile, during the quantitative analysis, the paper also gives the non-standardized parameter matrix cointegrating and adjustment parameter matrix. Finally, this paper presents a standardized cointegrating parameter vector and adjust parameter vector.

\section{Granger causality test}

From the above analysis that: Chinese virtual economy and real economic growth has a positive correlation, but the causal relationship between the two has not been reflected, i.e., whether the stock market development promote real economic growth or real economic growth promote the development of the stock market. Therefore, we must use Granger causality test to demonstrate.

Test instructions. Granger causality test is made by the famous American econometricians Granger in 1996, after a gradual improvement from the Hendry et al., and eventually developed into 
a test method check time series variables causal directionality. Granger causality test in variables shows in table 2.

Table 2 Granger causality test in variables

\begin{tabular}{|c|c|c|c|}
\hline Null hypothesis & obs & F-Statistic & Probability \\
\hline Ln(ca) does not Granger Cause Ln(gdpg) & \multirow{2}{*}{17} & 3.69 & 0.05 \\
Ln(gdpg) does not Granger Cause Ln(ca) & & 0.87 & 0.49 \\
\hline Ln(tu) does not Granger Cause Ln(gdpg) & \multirow{2}{*}{17} & 2.10 & 0.16 \\
Ln(gdpg) does not Granger Cause Ln(tu) & \multirow{2}{*}{17} & $\begin{array}{l}4.28 \\
1.06\end{array}$ & 0.03 \\
\hline Ln(va) does not Granger Cause Ln(gdpg) & & 0.21 \\
Ln(gdpg) does not Granger Cause Ln(ca) & &
\end{tabular}

Make the following assumptions:

$H_{0}: \mathrm{b}_{1 \mathrm{j}}=0(\mathrm{j}=1,2,3 \ldots \mathrm{k})$

$H_{0}: a_{2 j}=0(j=1,2,3 \ldots n)$

If the hypothesis is true, $F$ test statistic is: $F=\frac{\left(S S E_{\mathrm{r}}-S S E_{\mathrm{u}}\right) / K}{S S E_{\mathrm{u}} /(T-2 K)}$, if the null hypothesis $a_{2 j}=b_{1 j}=0$ is accepted, it means that $x_{t}$ and $y_{t}$ are independent, $x_{t}$ is not the Granger cause of $y_{t}$, nor did $y_{t}$; If $b_{1 j}=0, a_{2 j \neq 0}$ is accepted, $x_{t}$ is the Granger cause of $y_{t}$, but $y_{t}$ is not the Granger cause of $x_{t}$; If $b_{1 j} \neq 0, a_{2 j}=0$ is accepted, $y_{t}$ is the Granger cause of $x_{t}$, but $x_{t}$ is not the Granger cause of $y_{t}$.

Causality analyzes. The above analysis, various economic variables have been a smooth adjustment, and there is cointegration relationship between them. So Granger causality test can be carried out.

After look-up table: $F_{0.05}(3,20)=3.10, \mathrm{~F}=3.69>3.10$, therefore, it rejected the null hypothesis. $\mathrm{Ln}$ (ca) is the Granger cause of $\operatorname{Ln}(\mathrm{gdpg})$ changing, but $\mathrm{Ln}(\mathrm{gdpg})$ is the Granger cause of $\operatorname{Ln}(\mathrm{ca})$ changing, therefore, it is a one-way causal relationship between $\operatorname{Ln}(\mathrm{gdpg})$ and $\mathrm{Ln}$ (ca); Further analysis informed that $\mathrm{Ln}(\mathrm{tu})$ is not the Granger cause of $\mathrm{Ln}(\mathrm{gdpg})$ changing, but $\mathrm{Ln}$ (gdpg) is the Granger cause of $\mathrm{Ln}(\mathrm{tu})$ changing, therefore, it is a one-way causal relationship between $\operatorname{Ln}(\mathrm{gdpg})$ and $\operatorname{Ln}(\mathrm{tu})$; $\mathrm{Ln}(\mathrm{va})$ is the Granger cause of $\mathrm{Ln}(\mathrm{gdpg})$ changing, neither does $\mathrm{Ln}(\mathrm{gdpg})$, therefore, there is no causal relationship between $\operatorname{Ln}(\mathrm{va})$ and $\operatorname{Ln}(\mathrm{gdpg})$.

No causal relationship between $\operatorname{Ln}(\mathrm{va})$ and $\operatorname{Ln}(\mathrm{gdpg})$ shows departing relationship exists between the two sides. In general, improving the liquidity of the stock market reduce the risk of equity investments, in this case, investors are more keen to invest in some long-term projects, such as high-risk, high-return projects, which can mobilize substantial resources for productive enterprises, so as to spread the risk and ultimately to promote economic growth. Because China's stock market starts late and restrictions for various reasons, the enthusiasm of investors to buy new shares will be influenced by a floating market factors, which shows that China's stock market liquidity may not be governed by the stock market mechanism and improving the liquidity of the stock market does not promote economic growth.

\section{Conclusion}

Expanding of the size of the stock market will increase economic growth, from this it can be seen, in terms of the financing function, the stock market has shown some advantages. The current economic situation and the environment we live in provides good conditions for China's stock market financing function of further development. The increasing in stock market activity produces inhibition for economic growth, which illustrates the role played by the stock market is limited in useful information and effective supervision for listed companies.

\section{References}

[1] P.Y. Zhang. China Stock Market Research and Macroeconomic correlation between . Central Party School, 2013. 
[2] Z.J. Zeng, Z. Jiang. Researches on the impact of macroeconomic variables on stock prices. The Theory and Practice of Finance and Economics, 2007,01: 40-45.

[3] L. Liu, C. Xie. Z.J. Zeng. Empirical Research Stock Price Index and Macroeconomic Variables [J]. Hunan Normal University Social Science Journal, 2006,05: 82-86 + 104.

[4] Y. Xie. The relationship between stock prices and macroeconomic China. Office of Academic Degrees Committee of the State Council, the Ministry of Education degree in Management and Graduate Education Department. 2009 National Doctoral Conference Proceedings [C]. Office of Academic Degrees Committee of the State Council, the Ministry of Education degree in Management and Graduate Education Department: 2009: 16. 